\title{
Viable retirement solutions for the long-run: Are there any sustainable retirement solutions out there?
}

\section{Abstract of the London Discussion}

[Institute and Faculty of Actuaries, Sessional Research Event, London, 12 December 2016]

This abstract relates to the following paper: Richards, J., Hurd, M. and Clacher, I. Viable retirement solutions for the long-run: Are there any sustainable retirement solutions out there? British Actuarial Journal, doi: 10.1017/S1357321717000204

The Chairman (Mr M. D. Williams, F.I.A.): Welcome to this sessional research event entitled Sustainable retirement solutions: Are there any durable solutions out there?

I am Mark Williams and am a senior consulting actuary and London retirement practice leader at Xerox HR Services. I am also deputy chair of the Institute and Faculty of Actuaries (IFoA) pensions board.

To introduce our speakers, first, Jenny Richards who qualified as an actuary in 2008 and has over 10 years' experience helping pension scheme trustees and sponsoring employers to manage their pension schemes. She is an active volunteer with the IFoA and joined BBS from Punter Southall, having also worked for Hewitt and Watson Wyatt. Jenny is also on the pensions research subcommittee for the actuarial profession.

Second, Marcus Hurd who is a principal at Xerox HR services and co-director of the Retirement Decisions Group at the University of Leeds. He advises both trustees and sponsors of defined benefit (DB) pension schemes, specialising in financial risk management and effective decision making. His particular area of interest is helping trustees and sponsors achieve their objectives through flight plans.

Marcus is a qualified actuary and holds an MBA from the University of Leeds. He is regularly quoted in the media, including appearances on television and radio.

I will now hand over to Stephen Rees, who will be opening and closing the event. Stephen has 33 years' experience as an actuary and adviser on a full range of pension scheme issues. He has worked with a mixture of United Kingdom and global companies in a variety of corporate sectors and has held a scheme actuary practising certificate since they were introduced in 1997.

After 30 years at Towers Watson, he joined Capita in 2014, where he is chief actuary. As well as advising his own clients, he has responsibilities for professional standards, integrated risk management and assumption setting. He has recently accepted an appointment to join the IFoA's pensions board.

Mr S. P. Rees, F.I.A. (introducing the paper): The actuarial profession seems to have spent many years apologising for problems in the world of UK pensions rather than using its expertise to explain the reality of the situation. The profession has often been weak in its dealings with Government and in its 
efforts to influence policy. It is essential that we use our expertise to take command of the debate and influence social and economic policy. This paper is a big contribution in redressing that balance.

That being said, I disagree with the very first sentence of the paper "How individuals will achieve adequate retirement incomes is one of the key policy challenges facing government". This ought to be true. Unfortunately, Government policy has for many years prioritised regular tinkering with pension regulation, nearly always motivated by some short-term tax objective or media story. The need for our society to have a sustainable framework enabling UK workers and their employees to make sensible retirement provision has been neglected by both politicians and civil servants.

Regardless, if papers like this one enable us to have a clearer consensus on good ways of designing a pensions system, then it should become easier for us to influence the policymakers.

The paper is very much one of two halves. The first half offers a commentary on the situation that we find ourselves in; the second half offers some interesting analysis of a number of the options that might (or might not) be better.

The first half is slightly let down by a number of statements about the problems caused by the transition from DB provision to defined contribution (DC) provision. In many cases, the actual problem being identified is nothing to do with the design of the pensions; it is primarily to do with the size of the pensions. The authors are really careful with this distinction in the second half of the paper.

The authors make an excellent point about the need to be very clear with the definitions of risk sharing when we loosely talk about risk-sharing pension designs. Are we talking about sharing risks between members, or between generations, or between members and the employer, or something else?

The last couple of sentences of paragraph 3.1 are probably intentionally provocative. There are lots of problems with actuaries who think that they are following financial economic approaches but are in fact just using simplistic and questionable assumptions about return-seeking investments, and there are lots of problems with short-termism, but I am not sure that these points can be blamed in the way specifically described. It would be a shame for the debate to become distracted by those subjects when the paper has more important and newer things to say elsewhere.

Then we come to the second half of the paper, which I feel that we should concentrate on in the debate. In this part of the paper, we see some ideas that are an interesting way of looking at pension provision and potentially enabling there to be a dispassionate assessment of different pension designs. Because this has the potential to change the quality of the debate that we have amongst ourselves and with policymakers, I am hoping that people will express opinions about the model, assumptions and the maths.

There are of course weaknesses in the construction of the questions that the authors are choosing to ask themselves. That is inevitable when you set up any academic paper like this. For example, by concentrating on the risk of failure, the analysis does not focus on the best design for a pension scheme that does succeed.

And there are some niggles on points of detail, such as whether the use of a simplistic annuitisation factor of 20 for all scenarios undermines the analysis, whether we really can blame the EU for the primacy given to accrued rights and the need to explain the narrow definitions used in order to 
understand the conclusion on collectivism versus individuality. But, subject to some important caveats about the constraints applied in order to be able to conduct this analysis, it could be that paragraphs 8.1 and 8.2 become essential reading for any actuary who wishes to express an opinion about pension design.

There are some very interesting conclusions and commentary shown in the middle part of section 9 as well, for example, the potential damage to the UK economy of inappropriate pension designs, the conflicts of interest of regulators and the effects of state interference.

Perhaps the most important conclusion of all is the one about the need for clear communication. For many years we have allowed our clients, individual scheme members, regulators and politicians to be over-confident in the extent to which pension benefits are guaranteed. If we had been clearer about the futility of trying to guarantee everything at various times over the last couple of decades when employers or politicians were making important decisions, perhaps we would not be in the fantasy world that sometimes seems to exist in UK pensions. The solution to quite a lot of perceived problems might have been simply to explain the uncertainty rather than help to cover it up.

There is a lot for actuaries to discuss based on this paper and I am hoping that we will spend most of our time on the assumptions and the conclusions, and also on the extent that this paper ought to shape the way that actuaries explain matters of pension design to employers and with policymakers. Will this paper be the springboard for a more effective UK pension system in the future?

I look forward to the discussion.

Mr M. C.T. Hurd, F.I.A. (introducing the paper): The actuarial profession set up this working party in the light of defined ambition approach. Originally we were the defined ambition working party of the actuarial profession. There were 16 of us crammed into the offices next door as we debated this latest new initiative and what it meant for the world of pensions. It was not going to be DC; it was not going to be DB; it was the new way, defined ambition.

As political backing behind the move dwindled, so did our numbers in the working group until now you see before us this group of three.

The political motivations that prompted defined ambition have not gone away. On the one hand, we have overly generous DB pension schemes prevalent in the United Kingdom. I have already upset a few people in that one sentence. There is another one coming. Or we have wholly inadequate DC schemes which have been set up. I know that you can have something in between the two. But you have two extreme outcomes that are likely not to provide for the future generation of retirees.

That then begs the question: are there any sustainable retirement solutions out there? We moved to being the sustainable retirement solutions working party and this paper was trying to answer that.

A lot of the focus of people in this room will necessarily be on employer sponsored provision. That is what we classify as Pillar 3 (Figure 1). You cannot do that, though, without thinking about all the other pillars of income that individuals have available to them at retirement.

We classify five pillars. Every individual within the United Kingdom satisfying certain requirements will receive a basic state pension. So we have Pillar 1 instantly. 


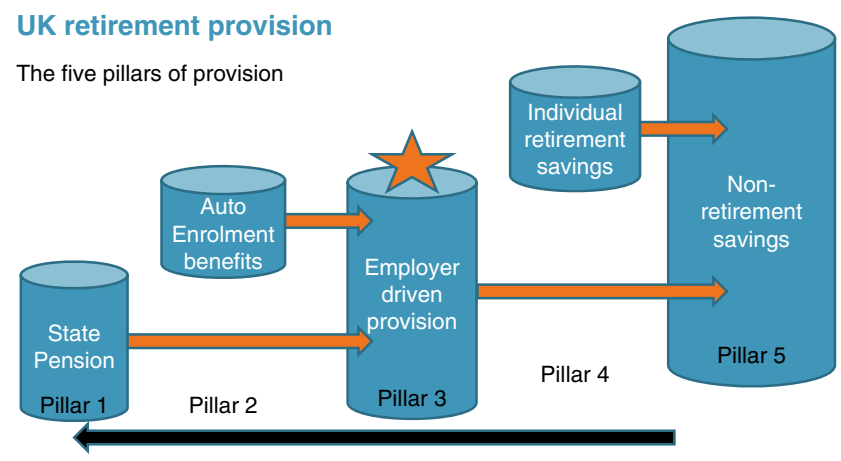

Figure 1. The five pillars of UK retirement provision

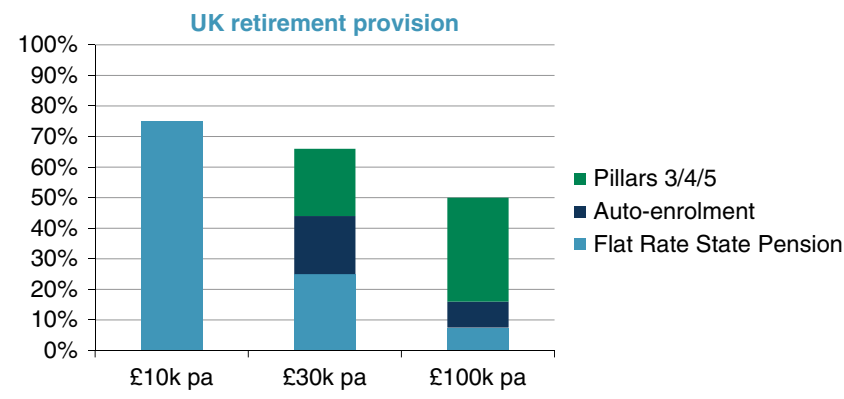

Figure 2. UK retirement provision: replacement ratios

In the United Kingdom, we now have auto-enrolment which has bedded in and has been remarkably successful in many respects. There are huge waves of the population which will be accessing income at retirement from auto-enrolment-based arrangements. We then have Pillar 3, where we as pension actuaries, tend to focus most of our attention.

Then individuals have individual savings which they could use at retirement. Indeed, with the pension freedoms I would argue that they are becoming more and more important in the way in which individuals think of this problem. Finally, non-retirement savings, the ethereal Pillar 5, which we may not feel entirely comfortable with, because it can be used for so many other purposes. But when you talk to the population as a whole, many of them consider their house to be their pension, or they intend to do other things, sell their yacht, for example, to fund their retirement.

We have all of these five pillars, and it is balancing these that we need to struggle with.

These pillars cannot be ignored. You will pick up from the paper that we do some simple arithmetic on what kind of replacement ratios those sources of income generate for individuals. Accepting the frailties of the replacement ratio and looking at this at top level themes, the basic state pension generates a reasonable replacement ratio for those individuals who are earning, say, $£ 10,000$ per annum (Figure 2).

If you accept that society considers it reasonable that there are individuals earning $£ 10,000$ per annum, then the basic state pension targeted as a proportion of that is also reasonable. 


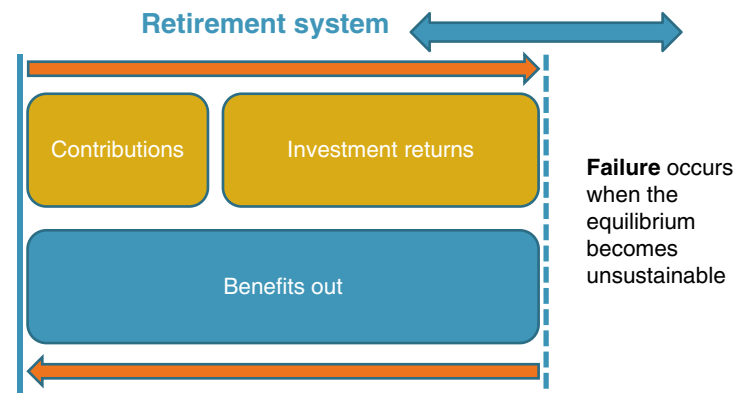

Figure 3. The golden equation

Similarly, something I find quite difficult to communicate on occasion is that the levels of income generated from auto-enrolment for the lower paid is a reasonable replacement ratio, particularly when we talk about auto-enrolment being wholly inadequate. We have to challenge that for those who were not earning that much in the first place.

If you increase auto-enrolment for those individuals, you could end up in a situation where they are achieving more income in retirement than they were in employment. I will avoid the societal issues but please do raise questions at the end if you wish to challenge that.

You are left in the situation where it is those who are somewhere between $£ 100,000$ and $£ 30,000$ who may struggle and need alternative sources of income.

That brings me on to the golden equation: contributions plus investment return equals benefits out (Figure 3).

If you are putting in a certain level of contribution and/or achieve a certain level of investment return that is the benefit that is available at retirement.

In particular, that draws upon the important principle if you are over-reliant on any one of those components, then the system starts to break.

That is an introduction, having almost posed the question, is it time to think about sustainability? What I want to do now is to hand over to Jenny (Richards), who is going to talk us through some of the model work we carried out and particularly the concept.

Mrs J. H. Richards, F.I.A. (introducing the paper): As Marcus said, the concept of the retirement benefit system is just wealth distribution. You have contributions and investment return and these provide benefits post-retirement. The aspect that differentiates between different types of retirement vehicle is the risk sharing. If everything goes to plan, a DC scheme looks exactly the same as a DB one, if you are putting the same things in and you invest in the same way.

What we were conscious of is the standard 2-D member, sponsor, risk-sharing diagram (Figure 4) was too simplistic if you are trying to look at risk as a whole. What is really important is risk mitigation. Reducing risk in a system as a whole is what is going to make the system sustainable rather than who picks up the risk on both sides. 


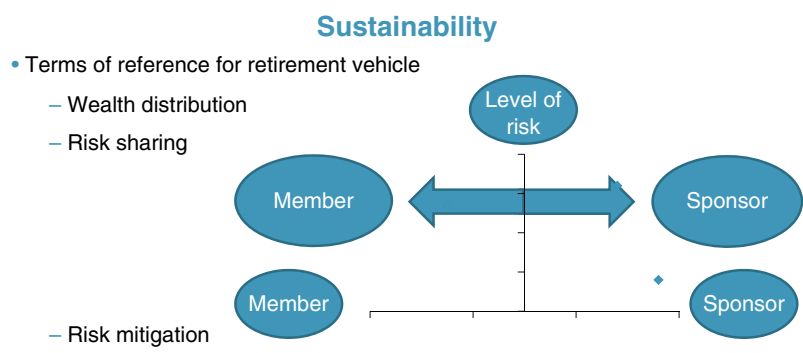

Figure 4. Risk sharing

We would suggest you are reducing the risk in the system as a whole and, in particular, we would note that in the extreme events, when the system fails, it has failed for both parties. If people abandon the scheme, if the sponsor covenant fails, it does not really matter who owed the contributions. The scheme is broken for members as well. Focussing on that is a secondary level that you need to be considering if you are trying to look at developing a system that is going to last for the longer term.

This is the modelling part. We were not trying to develop all the niceties around the model. What we wanted to do was to look at first principles and try to explore the differences between a DB scheme, for example, or a DC scheme.

Final assets are assets at the start of the year plus contributions, less benefits, plus investment return. Similarly, liabilities are just future benefits less future contributions.

We made some general structural decisions because we were trying to simplify the model before we started adding on complexity. At the first stage we modelled a single person and later we looked at the difference between collective or individual schemes.

We also set benefits and contributions to be a very simple percentage of an average salary which was increased with an inflationary index. The intention for this (pre- and post-retirement) was just a percentage coming in and going out, and it meant that the assumptions that we had to make around this are investment return, expected future investment return, inflation over the year and expected future inflation. Those four assumptions allowed us to explore what different things were affecting the sustainability of the retirement solutions.

We at this stage made the decision to exclude any demographic experience, our rationale being that the pre- and post-retirement periods act as a scalar. If you are pre-retirement for less time, you have got less money post-retirement, and the mortality aspect is not that dissimilar from an experience on an economic assumption going wrong. If you are exploring what happens if your funding level drops by $5 \%$ over the year, and what you do to remedy that situation, it does not matter if that is a demographic experience item or a financial experience item.

Second, we were conscious that one of the big decisions is about how you increase benefits postretirement. Initially we did adopt the increasing benefit automatically post-retirement with an inflationary index, although we did come on to look at that afterwards.

Referring to (Figure 5), this is a situation in a complete market, perfect world, where everything happens exactly as you think. If you do pay more contributions, more will come out. I would also 


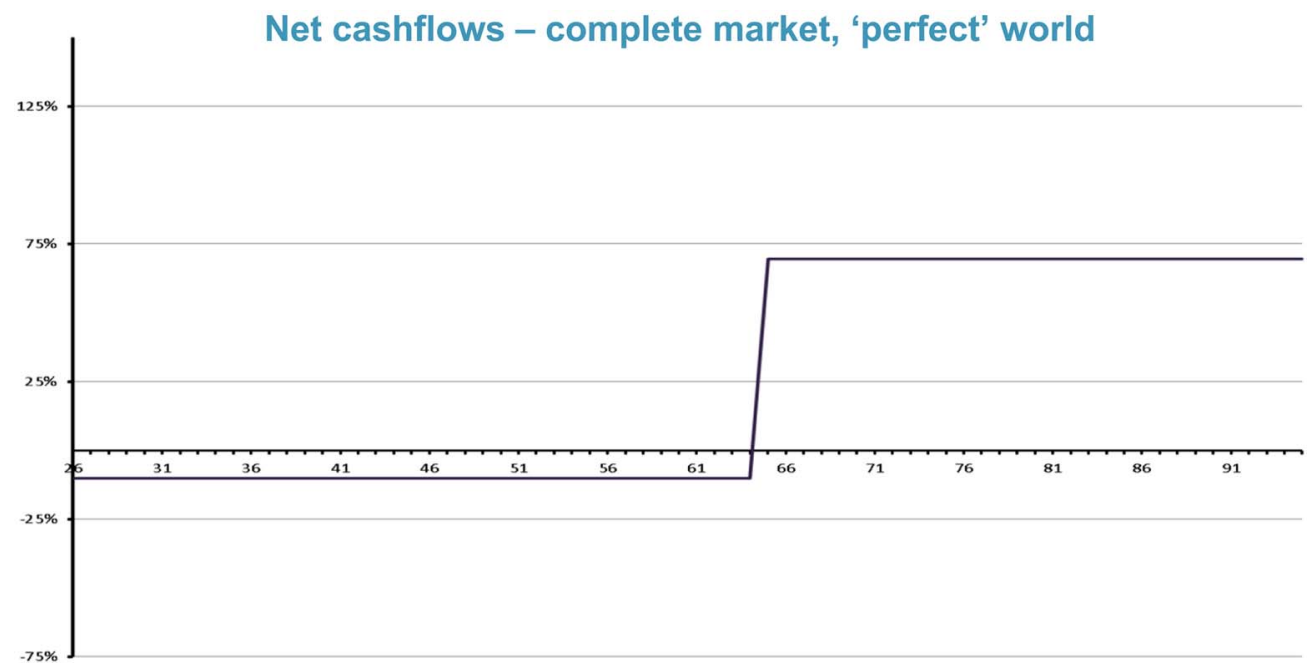

Figure 5. Cashflows for deterministic vehicle

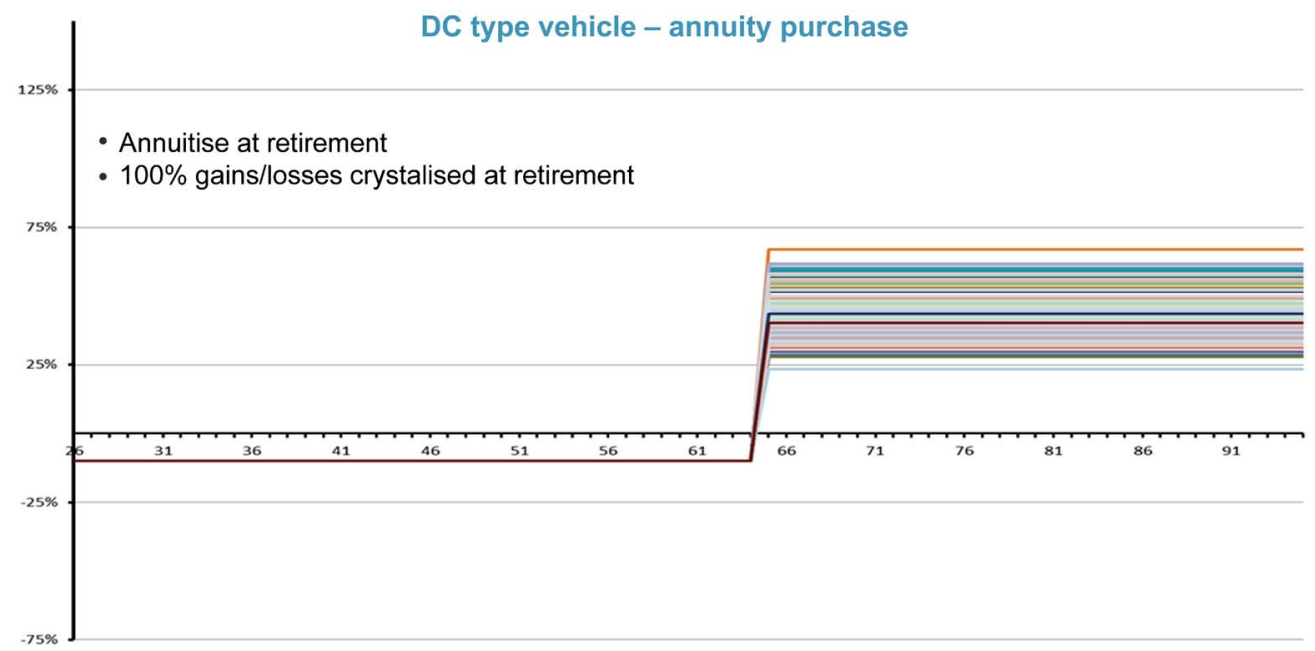

Figure 6. Cashflows for defined contribution vehicle

not focus on the period pre- and post-retirement because again if you are just there for longer preretirement, you obviously can afford more post-retirement. The main thing is that you can see the pattern that you have contributions going in during pre-retirement, which is the part below the line followed by post-retirement cash flows out. These are net cash flows so they are cash flow benefits less contributions. In the circumstance we have only cash flows in pre-retirement and cash flows out post-retirement.

For example, we have a DC type vehicle (Figure 6). This is where we were modelling those vehicles that currently exist in the market to see whether there were any problems inherent in those models. In a DC scheme, you pay in your contributions pre-retirement. At the point of retirement, your 


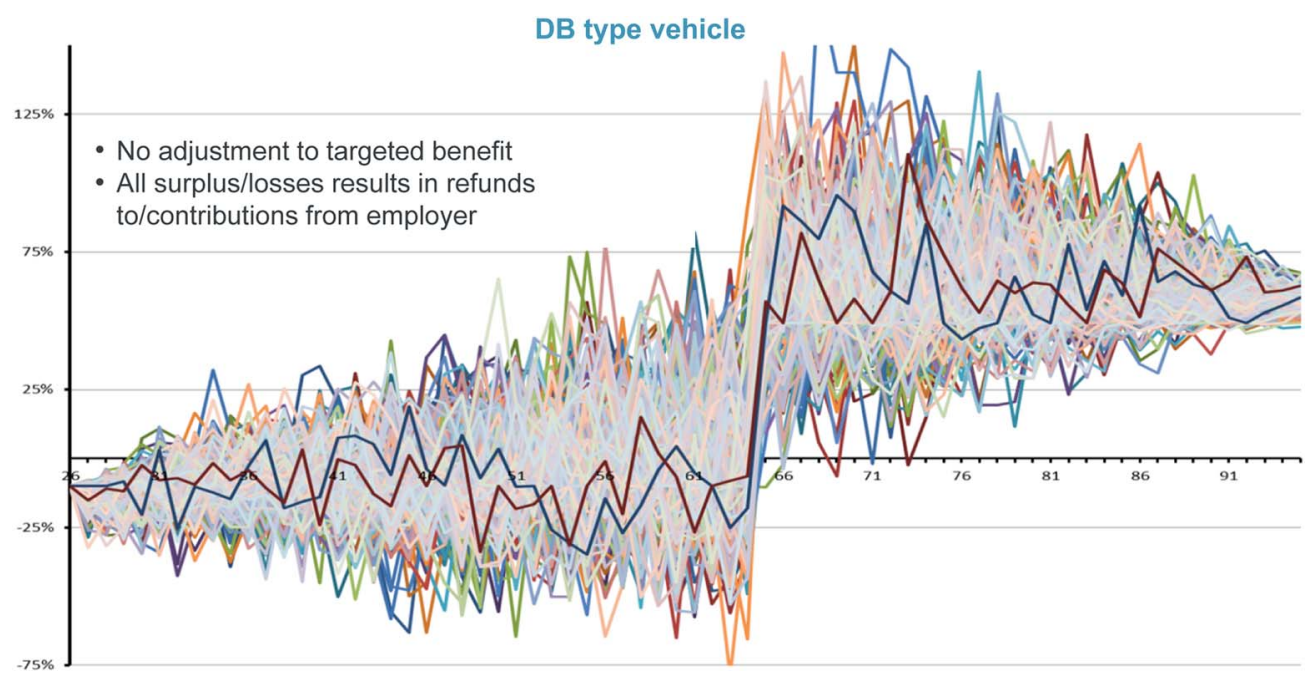

Figure 7. Cashflows for defined benefit vehicle

benefit is crystallised. The gap between the top and the bottom line highlights the problem with DC models. It is a lottery, depending on when you happen to hit retirement, but also just the level of the lines. While you cannot see them next to each other, the DB equivalents are all much, much higher. It is that amount that you are having to pay because of the investments you have to make postretirement in a DC type scheme and, obviously, the premium to insurers.

The third graph is a DB type graph (Figure 7). That highlights the problems with DB type schemes where effectively benefits are fixed. In this scenario, you cannot change benefits. All adjustments to funding level come from contributions.

The pattern of just inherent volatility is what we have seen over the period. This is particularly highlighted when we tried to draw from this a percentile of those different lines (Figure 8). Initially, you assume that there is going to be a funnel of doubt, and you can see which is the best case and which is the worst case, and this was what came out.

It is a hard to pinpoint what is the best case and what is the worst case. Do you take the net present value? What discount rates do you use? How do you define it?

I have plotted the best scenario and the worst scenario and they cross over each other in a number of places. In particular, I would note the $100 \%$ line, which is supposedly the best scenario.

It is the best scenario because quite close pre-retirement you get $150 \%$ contribution refund to the employer, which is what is driving it as the best scenario. If you backtrack, in year 40 there is a large contribution required from the employer. It is unlikely there is an employer that would say a $+50 \%$ contribution requirement would class as a best case scenario.

It is by looking at these graphs that explains the bulk of the modelling part of our paper; defining failure scores and trying to analyse what is it that makes a scheme fail: that is, what is it that makes it non-sustainable? It is characterised by the statement, either by the sponsor or by the member who is 


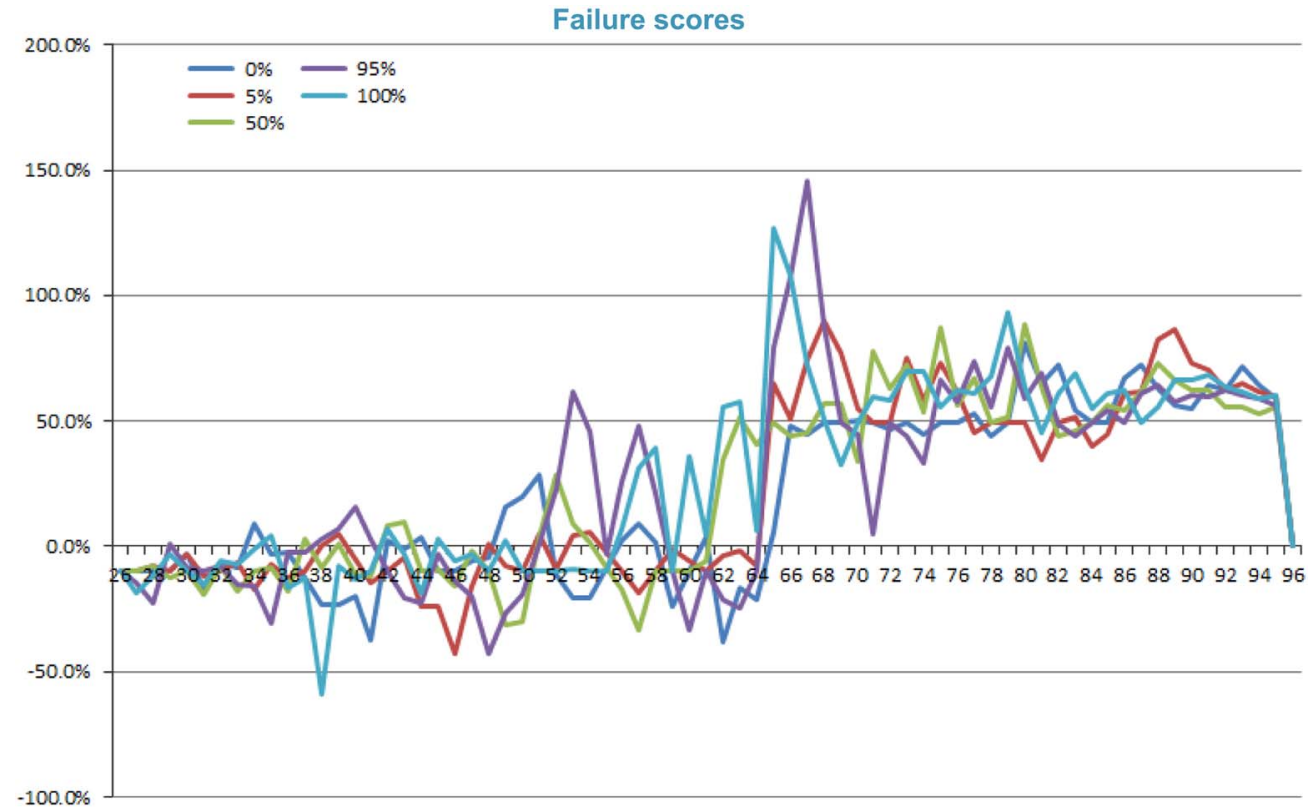

Figure 8. Failure scores

getting the benefit that "this is just not working". There must be an alternative, and that could be the employer just cannot afford contributions any more or members are getting to retirement age and they need something else or they are paying in pre-retirement and they can still see they are never going to get to retirement. It is trying to avoid that kind of binary outcome that is more important to people than just trying to work out whether they have $5 \%$ more or $5 \%$ less at any particular point, because if a scheme has just failed, there is no way that people can plan for retirement, which is the whole point around guarantees.

This thought process of that characteristic of things are failing can affect either contributions or benefits. Second, it can be at an absolute or at a relative level. Absolute is just fundamentally "My benefits are too low"; it is below $30 \%$ or whatever you think is your absolute floor in terms of benefit level.

You have relative failures. If you are being paid $50 \%$ every year in retirement, if that suddenly drops to $40 \%$, that $10 \%$ loss of income in that particular year would probably be classed as a failure, even if the actual level of $40 \%$ replacement ratio in itself would not be.

Using this structure, we went back to our model and tried to think whether there are any other things that we wanted to explore, and how could we look about the secondary aspects of when you are setting up a scheme, to see what drove sustainability.

You have the primary levers. These are not the same as the failure scores because they affect the same thing. These are the things that you can do instantly to restore your funding level back up to $100 \%$.

Benefits are obvious; you can change that. Contributions in this context means a one-off contribution of that amount. That is how you can restore your funding level back up to $100 \%$. 
Your secondary levers are those things that while you cannot tweak them and change the funding level, they do have an impact on how sustainable the retirement solution is.

The first one is recovery period. If you do not pay that one-off contribution and you instead spread it out, how does that guide sustainability?

You have investment strategy, and if you look at the paper and you look at the assumptions underlying it, we did not want to pin anything to this: "This is an equity strategy". "This is a bondbased strategy". It is more about how much does the expected future investment returns correlate? How well can you predict them at the point in time when you are doing the valuation? If you are looking at an insurance-type scheme, where you could have a good idea of how you can match your assets and liabilities, you can link those two quite closely, or you could have an "it is anybody's guess" type of assumption.

Prudence. How much does funding things on a best estimate basis affect the inherent sustainability of the retirement scheme? This makes sense in those kinds of schemes where there are no guarantees. That you can adjust up and down benefits and contributions. Part of the reason for prudence at the moment is that if the employer goes bust, you want as much money in there as you can, to then go and buy the benefits. In a system where you can adjust benefit, it does not quite make sense like that and is it a sensible thing to do funding on a prudent basis? This is when we started bringing in the collective versus individual schemes, looking at whether pooling your funding level across the whole of the system pre- and post-retirement, and checking the funding level and then adjusting everybody's benefits accordingly versus looking at each individual's funding level and tracking that separately.

We noted that all those levers only make sense in a theoretical world and there are likely to be plenty of political and regulatory influences not allowing you to do what would be a perfect solution. We were conscious that we wanted to explore everything because in the same way, as when the requirement for index benefits came in, you did not want members' benefits being eroded by inflation. Is it better to have an investment strategy that is invested in inflation-linked benefits that you can then grant discretionary increases as and when your inflationary linked benefits allow it, or to guarantee an inflation link, but only up to $5 \%$ when inflation is $20 \%$, you could have done better with the investment strategy.

It is important to revisit the theoretical conclusions in the light of any regulatory constraints, so we looked at things that might be slightly non-sensical but it was recognising that things are outside our control.

The primary conclusion is we labelled things "levers" in the first instance because they were things that you could pull. It was a good way of describing how they react because they are benefits - the fulcrum is much closer to the funding level. You need to do much less work to get it back up to a fully funded level when you are adjusting benefits as opposed to trying to do everything where the contributions need to work so much harder. You cannot capitalise your future contributions on the balance sheet at that point in time (or not reasonably) unless you can pay off things instantly, the amount you need to do to pay off with contributions is just so much more than benefits. That undermines the sustainability of the retirement solution, not being allowed to change benefits and this, importantly, includes the period post-retirement being wedded to the idea that pensioners cannot have their income adjusted downwards (and that is not just taking it away, cutting it by half) 
but to guarantee that causes so much instability in the system, where the realities for a few golden people were everything is fine but everybody else cannot provide for themselves.

Lastly are the secondary levers. This is where it got more interesting as you could look at why is that working like it is. Inflationary versus non-inflationary linked benefits. So our check about whether any failure score had been breached was on an inflationary linked basis. You were being checked against a benefit that was going up with inflation. There was little difference. In fact, not linking benefits and having the ability to effectively reduce benefits down below inflation, by far and away outweighed the benefits of guaranteeing your pension increases going forward.

It is a sub-set of the previous argument, but we were testing it against an inflationary link failure score parameter.

Second, best estimate versus prudent funding. It really does not make any difference to the likely sustainability of your system. This is in the case where you can obviously adjust benefits up or down. Given that one of the things that can really cause a pension scheme to fail is employers saying that this is just way too expensive, you are introducing more instability into the system by forcing people to value these kinds of systems on a prudent basis.

Considering collective or individual, made no difference to the results of the outcome. That should be focussed more on any social or any external factors: are there any desirable reasons why you would want to pool your experience? But in this context, it did not make any difference between the failure scores.

Lastly, volatility. While that was being inserted in our assumptions, it is obvious from the real world that you do not have a low-volatility or a high-volatility environment; things change. The failure scores, and what influences things, change depending on whether you are in a high-volatility environment or a low-volatility environment. Particular focus needs to be placed on how you manage the transition to these periods of low volatility to high volatility. It is not thinking that for these 80 -year vehicles you can make the decisions now and they are going to be suitable for the rest of the 80 years.

Nobody knows what is going to happen in the future. It is having those discussions around how things can change over time.

Then there are some other minor points. Regularity of assessments. This is to do with your recovery plan. The speed at which you sought to get back to $100 \%$ funded only really affects situations where you are in a deficit. Your deficit is what causes the failure score parameter. It does mean that any decisions about how quickly you restore surplus, did not really seem to undermine any future calls on that surplus if things then went the other way.

The impact of the life-cycle. That decision was more important pre-retirement than post-retirement. That is mostly to do with how many years of capitalisation of things you have going forward. One of the things that would be interesting to explore is while we split things up between pre- and postretirement, to look at different parts of the life-cycle of the scheme, to see when these decisions are most important and when it does not matter as much.

The acceptable fluctuation buffers. That is, if you assume that you give schemes a bit of a leeway, that you do not make them change from $100 \%$ funded at all possible points in time, if you only 
change benefits and contributions if they go over, say, $110 \%$ funded or below $90 \%$ funded, does adding that buffering, which is preferable to members because it is less volatility, affect the sustainability? And, in particular, how does it affect when you are funding on a best estimate or a prudent basis? Again, on a best estimate basis, it did not make a huge amount of difference but on a prudent basis you could see the difference between the two. That seems to be solely driven by the additional instability caused by introducing prudence when it was not helping the situation.

The last point is a social point; it is a member-specific point. We set the failure parameters how we wanted to, and we set the salaries going in. Where those members had a particularly narrow income stream versus what you would have otherwise have expected, none of the decisions about how to adjust benefit, how to fund it, really made any difference at all.

For those kinds of members, decisions need to be made in a different way from those members who have a much wider background. It is important to look at the profile of the members you are designing the scheme for, not just assuming that one size $60^{\text {th }}$ pension scheme suits everybody.

Mr Hurd: The paper was never intended to be a modelling paper but to focus on bigger themes and conclusions to be drawn; what model you use is unimportant. No matter what model you use, as long as it shows volatility, the same concepts are drawn out. We used other models as well. The same conclusions came out.

So on the back of it not being a modelling paper, there were four key features that we thought should be inherent within any retirement system if it is to be sustainable for the long term.

The first is around cost generational subsidies and the desirability or otherwise of that. In particular, in light of the current retirement system, a recent report showed not only do retirees now have a greater source of wealth in the UK proportionately than various pre-retirement, they now have higher incomes post-retirement than employees did previously. We have some serious questions about the way in which this has occurred and how you reverse back from that situation.

Is it right that you have cross-generational subsidies to that extent?

The other point, which is important, is linked to relative wealth. "How rich is my neighbour?" If you are on a street and you are the only person on that street who does not have a car, you have low selfesteem or feel "poor". When you look at psychology texts on this, you find it evident.

If you are the only person on the street that does not have a swimming pool, you will suffer from low self-esteem. If you are the only person in the county who does not have a helipad, you will suffer low self-esteem.

It seems quite trivial but the point is valid. When you look at social standards across the United Kingdom, in fact, living standards have improved considerably. It is relative wealth that troubles people.

If you have distortions in relative wealth, you end up with societal problems sometimes leading to revolutions with overthrows of government, and so on.

We are not so far away from that, when you consider the riots in 2008 during the credit crunch, the latest elections going on throughout Europe, possibly the Brexit vote and the election of Trump. I am 
sure that you will all have your own views on it. It stands the test of time that where you have problems with relative wealth, you have greater problems on their way.

One other thought to consider. Desirable, sustainable outcomes for investment of funds. There is over $£ 1$ trillion worth of UK assets in retirement savings. It is clear to me that any sustainable retirement solution has to make good use of those funds and allocate them in a way that is good for society as a whole and also individual engagement. If you accept where we are as a nation and the trend towards individualism away from paternalism, as we have seen over the past 30, 40 or even 50 years, then it is clear that you need individuals engaged within this process, because it is the individuals who are responsible for making these decisions.

Those are the desirable features. Let me summarise our conclusions.

Is failure inevitable? Jenny believes that if you heed the lessons from the past and design a retirement system based on what we have learnt, then you can design a retirement system that will stand the test of time and be sustainable. I do not believe that is the case.

I believe that it is inevitable the system will fail because there will be a period of stress during a 100-year time horizon that we cannot predict and the system at that time will not be able to withstand without breaking it and restructuring it to a completely different extent.

Therefore, I argue, an actuary is designing a retirement system for failure, so you should design it so that when you come to failure, you know exactly what you are going to do at that point.

The truth will come out when we come to questions but probably lies somewhere in between the two. Social change is critical. The move to individualism is one-way, as it is hard to see that reversing. If individuals are now responsible for their own retirement, we need to reflect the social change that goes along with that, not just in terms of retirement products, but in terms of the next point, financial education.

We have moved from paternalism in the United Kingdom. Now we have done that, we have to educate our people to enable them to make retirement decisions.

I also want to talk about risk sharing mechanisms and what the modelling shows. Whether it is DB/ DC, is it the responsibility of the providers? That is the market that we seem to have ended up with, whereas it is the people selling these products that are on the brink of designing the next generation of retirement solutions. That should be something the profession is building.

In fact, whether you agree or not with defined ambition, which is where all this started, the idea that we jointly build something for the future generations seems a sensible move.

Finally, there are other considerations which I conclude are not actuarial issues but ones that we need to be acutely aware of because they override all of the actuarial niceties.

The first one is macro-economic goals and, in particular, around investment in the growth economy. We are in a situation where you have $£ 1$ trillion worth of retirement savings and we are in real danger of them all going into closet index tracking funds. I argue that $£ 1$ trillion of investment can be used a lot more wisely by government as a whole if it is appropriately invested. 
How do we create a mechanism whereby that $£ 1$ trillion can be to the benefit of the UK economy? If government ignore that macro-economic goal, we are really missing a trick.

There are also the other political needs at the time. I have been brought up to think about retirement savings, adequate incomes, people retiring; but when we complain about government making shortterm decisions, whether it is pensions freedoms, whether it is tax relief, they are not doing it for bad reasons. We with our retirement savings hats on may object, but there are wider political needs at the time which take priority. When government make policy decisions, they are doing it, we hope, because there are wider political needs that take priority.

My argument is the retirement savings priority will come back as and when it starts to become a more pressing issue. At that point, we as a profession need to be there to stand up and make our voices heard in the same way that we need to be heard now when things are not going in the direction of retirement savings.

Whatever we do, there is a need to share wealth in a fair and proportionate way. One lesson we have learnt from the modelling is you cannot just have a system where some people gain enormously and others lose out considerably by effectively paying not only for their own benefits but also the generations that follow.

We have two question marks here. I am in two camps. The first conclusion that we drew is that whatever retirement system we set upon, should be free from political direction. Our original thinking there was that when you go back to where we started, it was the political tinkering that broke the system. But then the more you think about it, the more you think about the political needs of the day, how crazy is it that you have $£ 1$ trillion of pension assets and a huge gaping debt in society and you cannot touch one to remedy the other societal problem. You can end up with a ridiculous system where you have a brilliant retirement system but people not being able to afford to get into work in the first place.

We started off thinking it had to be free from political direction. We are not so sure by the end of our considerations. This is linked to the government's ability to cross-subsidise and tax, as well. In reality, there is a happy medium somewhere between the two. Somewhere between government being able to make changes to reflect the needs of the day and another way they report to some higher body, in their deliberate tinkering of the retirement system, I am sure most of us would agree it is government influence that largely broke the DB system.

Ultimately, when you pull all of this together you see that there is a lot of thinking going on, together with a lot of modelling.

The ultimate point that we come to after all of this is that we need flexibility within whatever retirement system we design. The onus should be for us, as actuaries, to design it. But the real challenge is how do you ensure that that wealth is shared in a fair and proportionate way to all the stakeholders involved?

Mr J. G. Spain, F.I.A. (opening the discussion): To see the word "sustainable" is good because actuaries used to be the only profession that even thought about it. I was worried before the presentation about the lack of data, just one asset return, and also using the normal distribution, which is completely wrong. But it probably does not matter for the purpose for which you are using it. 
You referred to the difference between prudent funding and best estimate funding. We need to remember that unless you know what your best estimate is, you do not know if something is prudent. People seem to think that investing in bonds and assuming you are going to invest in bonds, with an appropriately linked discount rate, is going to solve it. It does not.

In fact, it is discounting that is the problem. Way back, discounting was all we had. It was the only way we could get some sort of handle on future cash flows. That is not the case anymore. Discounting hides what is happening. We should be looking at stochastic processes much more. Asset Liability Modelling got a bad name in the 1970s/1980s. It is now respectable, and we should be using it more.

There was a lovely quotation by Keynes right at the end of the introduction: "the difficulty lies not so much in developing new ideas as escaping from old ones".

The problem we have at the moment is escaping from a new idea. In 1921, the Inland Revenue started giving tax relief on employer's contributions. These things have been around for a long time. But it is only in the last 15 years or so that mark to market and discounting at really low rates of interest has become so ingrained in the UK actuarial conscience.

If we can get rid of that idea, that would give us the flexibility.

Mr Hurd: Thank you for that input. One interesting observation when constructing the paper on that point about asset liability modelling in the stochastic world: none of the systems failed deterministically. You are absolutely right. It is only when you start to consider stochastic analysis that you can design a sustainable retirement solution.

Mrs Richards: To take your point about the discount rate, it is not as simple as having a discount rate that is not mark to market. If you cannot reduce benefits post-retirement, unfortunately you are still inherently going to fail much more frequently than otherwise. You need that lever regardless of how the basis is set.

Mr T. W. Keogh, F.I.A.: I will make a contrary point. One of our big problems in all of this is to overstate the importance of the investment return and the uncertainty aspect of it.

To me the reason why DB has proved unsustainable is that it is unrealistic to make long-term commitments over 80 years that are even vaguely fixed regardless of the funding mechanism.

I suspect that such commitments look less risky for an unfunded scheme than a funded one. This is because with the funded one we introduce the extra idea that investments will do a lot of the "heavy lifting" without necessarily fully considering the risk. We should also consider the extent of commitments on the economy as a whole, and start thinking whether it is sensible to make these very long-term commitments.

Rather than doing deals with our great grandchildren, would it make more sense to organise things 10 or 20 years hence, which is probably a bit more sustainable. Perhaps we should focus on that, which leads to the end of the spectrum with enhanced DC rather than DB-lite. So risk sharing over a limited period of time - this might be more about the decumulation period, and an annuity is an example of that, but there must be others. 
My main thought is - do not get hung up on the investment side; think about the overall deal being done.

Mr A. B. Pepper, F.I.A.: I wondered whether people are aware of a recent court case (O'Hare v Coutts Bank). The point about the case is that it is the only case where the judge discussed how much information a person needs to know to decide whether some investments are too risky for them. That it is an important case to bear in mind.

Mr P. D. Robertson, F.F.A.: I should like to take you to task on a couple of points which are about target market.

The first stems from the tax relief point. You have three scenarios, $£ 10,000, £ 30,000$ and $£ 100,000$. I would argue that, despite the 95-odd years of tax relief, pension scheme design is all about the integration with tax and the government should not have an interest in providing tax relief for people who are earning more than, say, average earnings. Whether that is a socialist point or not, that is what the Americans think, too. They would not give anything like that.

So, if you are going to have a sustainable system, you should say that you are trying to provide a part of that. So for the $£ 30,000$ person, half of it is state pension, half of it may be from the pillar that you are trying to design.

The second point is about longevity. Many of you will have heard about 'The 100-year life' book. The idea that people born in the past 20 years are probably going to live until 100, on average. So pension scheme design, as we traditionally think of it, goes out the window. You do not want a fixed benefit if people are going to be dipping in and out of work or in and out of careers later on.

You have two very different things that really challenge the way we have been dealing with sustainable pension schemes. We are looking at everyone, and it should be a much lower benefit and we are thinking that people will get an income for life, where in practice they are going to be dipping in and out of the work place. You need to design a pension that fits that.

Mr Hurd: Those are two very good points. One of them in particular we considered at length.

I will stay free from political direction regarding the appropriateness or otherwise of taxable income brackets at different rates.

The key is by implementing split rate taxation, what the government are trying to do is target certain sectors of the population and encourage or discourage them from taking certain actions. They are taking a macro-economic view and a year-on-year view regarding what kind of retirement savings they want in the population. If you go down the split rate approach, which has its merits, what you are saying to those with the lower pay packets is retirement savings is important. We will therefore incentivise you to do that. We will take taxpayers' money to subsidise that. But similarly, saying to the higher earners, retirement savings is not important for you, we would rather you go and do different things with your money.

The point whether or not we do that is extremely important. I put it within that wider government context regarding what they are trying to encourage within the population as a whole. 
The second longevity point we removed from the final paper. It was discussion regarding the fact that people are living for 100 years plus and the actuaries' concept of retirement is broken altogether. We argued that the concept of retirement is now completely gone. You are not going to get people being born today who will retire at 65 or 70 or 75 . None of those ages will apply.

We will have social change whereby the cost of retirement is too great. You cannot set aside funds to cover the whole of retirement. What they will do is they will downsize in the years prior to retirement. In reality, when you reach age 60 , you go to 4 days a week. Frankly, the extra income that you get from the fifth day is just not worth the effort. Then a few years later you go down to 3 days a week because frankly even 4 days was too much by that point.

You reach a point in your life, and it is part of natural evolution, where in fact the individual slowly retires, and retires to the level of work that they are willing to do to justify the income that they wish to spend in the context of their wider savings.

We edited that from the final paper because we decided that it was a distraction, although we fully accept that it is an important point when you are trying to design future solutions.

Mrs Richards: I would pick up those points in the context of the modelling. Different types of people, the leaders, act in slightly different ways. It is only by thinking about the five pillars and what the scheme you are talking about is trying to achieve and therefore what counts as a failure for you for that particular scheme. That comes into what tax is affecting things, and also when you get to retirement, exactly what are you trying to replace, and therefore where your failure lies. It is only by having those thoughts and making sure that you are targeting the schemes to the right type of person, that you can then explore what the right levers are and how best to deal with them.

Mr J. Instance: Are we ever going to be able to work for 5 days a week? I just wonder whether other things are going on within society, coming back to the earlier point. Are we designing a sustainable pension system for a way of an economy or a way of life that is already very close to being superseded in any event?

This is a really interesting paper. Are the challenges bigger than we are looking at?

Mr Hurd: There is a bigger problem with what effectively leads to high levels of unemployment. You could argue that the whole capitalist society is broken. The problem is at the moment organisations are seeking shareholder value and the way in which you do that is you reduce your cost as far as possible to the same level of output, or you increase output with the same cost base. You end up with a bit of a problem where you can automate a process. You increase profitability. Therefore you push up unemployment because you do not need individuals to do that.

High levels of unemployment are socially very undesirable. Where you have high levels of unemployment, you have a lot of people who are disengaged. How do they generate income? How do you then have levels of taxation to keep them not working? You cannot have waves of population in extremely poor circumstances; that again leads to social unrest and revolution.

Maybe there are lessons that we can take from other countries in the world which do not target high profit/high shareholder value but target high levels of employment where in actual fact their model is 
how do you keep society occupied, not how do you chase shareholder value; but we are going beyond the remit of the paper.

Mr Pepper: I would like to supplement the previous speaker's point by suggesting where are we going to live? Even if we are in work are we going to be able to earn enough to afford rent, let alone buy any housing?

Mr Keogh: May I be a bit more optimistic and suggest that the point here is that so long as we can create enough cake, it need not matter if only one person is employed making that cake so long as you then set up a system to divide it up? I am not saying that that is easy but it should not be insoluble.

You rightly mentioned all the different pillars. Have you looked at diversification in the pillars and the implications of that for the sustainability? If only one pillar fails, it is not so bad if people have spread their risk. But at the other extreme, if all the pillars go down together, it's a bigger problem.

Mrs Richards: Only to the extent that that dictates where you would set your failure parameters. You have a lot more ability to accept fluctuation if you have a high level of guaranteed basic state pension and another guaranteed part. The bit that is sitting above it can be a lot more volatile.

Mr Hurd: On the specific cake point, it is all well and good if there is enough cake for everybody to eat, but what do they do in between eating the cake?

Mr Pepper: You are suggesting that it is a solution to do away with guarantees. If you do that vulnerable people will take legal action.

Mrs Richards: Yes, so that comes back to the education point. It is not just about educating individuals, it is educating the regulator and the government and keep re-educating them that with the introduction of guarantees (and when things change), what the implications of doing that are and that it can fundamentally undermine the system. That is not a fool proof answer. Obviously, it is when government tinkers with something that was working perfectly well, that things break.

The onus is on us, as actuaries, to keep, or start, shouting out when we can see that the government is going to do something that is expected to disrupt the whole system.

Mr Hurd: That is a good point. I deal with a number of international schemes. Even at an international level, there is a legal principle that you cannot take away a benefit that you have already awarded during employment, which is really problematic. There are only a few things that you are allowed to do with a promise that you have already made which I think is part of our motivation. You need to avoid the guarantee because if you have not promised it, then you are allowed to take it away. It is really nuanced and complicated.

Mr Pepper: If you do not have guarantees or if you try to take them away, people might well have a legal case. This could well be based on common law. It seems to me that actuaries are extremely weak on common law. There is a great gulf between actuaries and lawyers. Actuaries are not as well up on common law as they should be. The lawyers do not know that these premiums exist so they do not even think about them. 
This is definitely happening. We know the sort of decisions that the ombudsman is making. He/she is consistently unable to consider probability points. We know that very well because we have a whole list of decisions by the ombudsman that got probability points completely wrong. They made completely the wrong assessment.

Mrs Richards: I will take your first point which is one of the things that we did identify with the modelling, that we can come up with the theoretically best solution but there will always be external constraints because we are not lawyers. Things will sit around it. The importance is not stick with what was originally theoretically correct and just run with it; you need to reassess everything again because that is when it might have been a different lever, a slightly different construct that would be optimal in this not theoretically perfect environment.

So it is really important to be aware that you cannot do what you want to; reassess and make sure that it is still the new optimal solution.

Mr Keogh: The bit of Marcus's position I liked was to plan for failure. No one believes the naysayers until something does fail. That is one of the lessons of financial history.

It might be better if some people have vaguely thought about what the failure mode might be, and whether failure will be an absolute disaster or just a bit bad.

One of the lessons for me in what has happened in DB is that we left it too long to regulate it and to cut back on the level of the 80 -year promises, and therefore it is now failing quite hard. It might have failed more gently, for instance, if everyone stopped in 1997 and said "No, we will stop accruing if the alternative is guaranteed index linking" which everyone had the option to do. Hardly anyone did.

Therefore it is the failure mode, and how you deal with that, that is important.

Mr A. M. Slater, F.I.A.: I want to pick up on some of the recent comments. We do plan for failure in many other walks of life. That is what is missing from the pensions conundrum. That is why if we can find a practical way of bringing that in, that just requires human beings with the wherewithal to do it, we can fix the problem. So theoretically, I am an optimist. Practically, I am sitting on the fence.

It sounds as if we need to change the tax system to tax robots, and that solves all the future problems of employment. We sit around eating cake, playing around on Facebook and waiting for diabetes to kick in.

Mr H. R. D. Taylor, F.F.A.: There are some very interesting concepts and it is something that we should certainly take forward as a profession. It is something that is understandable to politicians and the general public. I like the concept of the five pillars, the distinct and the individual qualities.

My point is that one big thing that is changing in society is the adoption of technology and the extent to which people are using mobile devices; the extent to which artificial intelligence is coming into decision making and engagement.

I just wonder what the view is of the panel about the role of technology and the way it is fundamentally changing the shape of society and the way that society engages in the big issues that will affect people's lives. 
We are massively underestimating the impact that this will have over a relatively short timescale. If you look at the changes that there have been in the last 3 years, in the last 10 years and in the last 30 years, it is one of accelerating change. There are many areas where there is a role for the right technology leading to a better understanding of human behaviour and the science around how people become engaged and make better or worse decisions.

Mrs Richards: I agree with you. Certainly it links into the importance of educating people. My main concern is that not enough work has focussed on understanding how people's minds work and what drives them by the people who are developing the software for pension schemes.

There is a big problem around educating people in general in a way that is going to engage people in the scheme. That is being driven by people who understand pensions and understand financial matters without thinking that you do not need to understand the nuts and bolts. It is more understanding the behavioural economics behind it and trying to design technology that really will engage people. That is the big challenge, as it appears to be lacking at the moment.

Mr Rees: I support that. The big step has to be something to do with the education of people who have not made much effort or been given the chance to engage with an understanding of their own pension saving arrangements.

Even quite recently, we have seen the problem with what is called freedom and choice. You do not have to buy an annuity that makes sure that your money lasts as long as your life. That sounds great and flexible. The branding, freedom and choice, how positive does that sound? Yet if you do try to explain it is difficult; for example, pensionswise, on their website, made a decent effort at using technology to explain the fact that none of us know, however, much we have studied the longevity statistics, how long we are going to live and how long we are going to need our money to last. We can do better at using technology now that you can illustrate so many more things in so many better ways to explain to people that this is what you are facing with your non-working life and how long your money is going to last.

We can use it by improving the quality of decisions taken by individuals, which in turn might improve the quality of design made by employers and by government.

The Chairman: What is not needed is to continue current, or past, ways of engaging with the public on pensions, as these approaches are not working.

People are not engaging in pensions. What is needed is to look at things that people do engage in and try to learn from that. At this time of the year people engage in Amazon, for example, to buy their Christmas presents. Why do people do that?

Learn from the things that the public do engage in and apply that rather than try to tinker with what is there that is clearly broken.

Mr Slater: I agree with the point about technology. The guys in Silicon Valley do not appear to understand human beings and how they behave. They are building systems that work only if people behave truthfully and honestly. And, guess what? We do not. That explains why all the pollsters are wrong.

More education is always needed and any solution that requires education to work is doomed to fail. It just does not work. If you rely on education, you are setting yourself up to fail. 
Mr Spain: The word "guarantee" has been mentioned a number of times. It was in the mid-1970s when maturity guaranteed surrender values became a hot issue at the Institute and Faculty of Actuaries.

The trouble is most people do not understand what a guarantee is. It is not $99.5 \%$ even, it is $100 \%$. Whatever happens you are going to deliver. Very few entities are truly in that position. It is not explained to the members.

I do not know who can explain it to members, sponsors, trustees, because I do not think actuaries understand it that well. They are still using determinism to say that this is a number without explaining where in a potential range this number might belong. Is it a median or mode? Is it $10 \%$ up from the bottom or down from the top? You will not get that sort of information.

Think about when the revaluation rate was set for guaranteed minimum pensions. The first fixed rate was $8.5 \%$. It is an unimaginably high rate now because no one could see what was going to happen.

I can remember people telling the Inland Revenue that they had assumed that inflation would be $3.5 \%$, because that is what it had been, even for benefits which could be capped at five. They just were not looking at the possibility that something else might happen. Unless we can educate ourselves, I do not see how we can possibly educate anybody else. I do not see anybody else out there who can do the education, either.

So, I have gone back more to the pessimistic side.

Mr Taylor: One of the developments that is currently underway, which has the potential to increase engagement if the information is used in the right way, is the pension dashboard. It is encouraging to see the number of large institutions that became involved with the Association of British Insurers when this was kicked off. A few weeks ago another six major institutions joined the group. There is a real weight of major institutions which are engaged now.

The government and the civil servants have left it to the industry to come up with something. If it is fit for purpose then there will be minimal intervention. I hope that it is because further government intervention would be bad. It would be even worse for the UK population who are relying on the pensions industry behind the scenes unknowingly to be doing the right thing for them. I am not sure whether you agree or disagree. It will be some time before the pensions dashboard hits the streets. These things take a while to build. From what I have heard, I am reasonably encouraged.

Mr Rees (closing the discussion): We have had an interesting set of opinions and comments expressed on what looked like a very specific subject that was being analysed.

One of the most important conclusions of the paper is that having no power to change benefits is extremely unhelpful when you are trying to design a sustainable system. That does not mean that DB pensions are a non-starter because you can design a system where the intended level of benefit is different from the committed level of benefit. It then becomes a requirement to be much more thoughtful about where to set the different levels and the fact that those levels are different from each other, just like they used to be before the 1990s, when there was very intentionally a difference between those two things. 
What it does mean is that we do need to analyse more than we have done, and this is one of the next stages to be worked on: Where exactly the risk sharing should fall between the extreme points? Tim Keogh pointed out a reason why we might need to be nearer the pure DC end than the pure DB end. That is something that we need as a profession to look at a bit further before we can speak with a clear and consistent voice in the outside world.

We need to improve our explanations, but first understand when collectivism is a good thing and when it is a bit irrelevant. It was an interesting conclusion to reach. In fact in certain situations, collectivism was not an essential feature. There are obviously other situations where it is, such as annuitisation. So trying to be clearer and to have greater consensus on definitions of when collectivism is a good thing merits further work.

We have had our debate about whether we should plan for failure, even if we came up with a pension design system that was more designed to be sustainable. I do not think it was overwhelming, but it was a majority definitely in favour of planning for it all to go wrong and knowing what you are going to do in that situation.

We had a few strands in terms of communication issues - communications among ourselves and with policymakers. We have to spend a bit of time wondering if we can explain to politicians the concept of replacement ratios. Is that a concept which is well-established? I am not sure that it is.

When we are talking about things like tax relief, are we in fact meaning tax deferral? I think as a policymaker you could very easily, just with that one change of word, come to a different conclusion about what you thought was the right conclusion about whether it is tax relief or tax deferral when we are doing pensions saving.

Can we, or indeed should we, stop politicians from making knee-jerk decisions when it comes to a pensions framework?

Overall, there is still hope that we can collectively use this work to get better at explaining pensions design choices to the government and to employers. I am keen that this work is continued.

The point at the end that Harry Taylor mentioned was quite pertinent about technology and what we are going to do with that. We need to consider how we can be involved in using that to make sure if it does come down to financial education, how it can be used and how we can contribute to it being used for better decision making by individuals, which could change the whole framework.

The Chairman: It remains for me to say a big thank you to our three speakers, to Jenny, to Marcus and to Stephen, on behalf of myself and everyone here and to thank you to those of you who have contributed to the meeting. Thank you very much. 